\title{
Trends of HIVIAIDS Epidemic and Awareness Levels in Bangladesh
}

\author{
Omar Faruk, Najma Begum, Shohel Rana* \\ Department of Statistics, Noakhali Science and Technology University, Noakhali, Bangladesh \\ Email address: \\ nstu.stat@gmail.com (S. Rana) \\ ${ }^{*}$ Corresponding author \\ To cite this article: \\ Omar Faruk, Najma Begum, Shohel Rana. Trends of HIV/AIDS Epidemic and Awareness Levels in Bangladesh. International Journal on \\ Data Science and Technology. Vol. 3, No. 6, 2017, pp. 56-65. doi: 10.11648/j.ijdst.20170306.11
}

Received: September 26, 2017; Accepted: October 27, 2017; Published: November 5, 2017

\begin{abstract}
This paper observes the level and trends of HIV/AIDS epidemic and its awareness in Bangladesh. The HIV/AIDS prevalence rate in Bangladesh is $0.01 \%$ and in compared to other neighboring countries Bangladesh has least prevalence. The trend of HIV/AIDS prevalence in Bangladesh is increasing. The highest prevalence rate is found in Nepal and its trend is found decreasing over the years. The trend of number of death due to AIDS in Bangladesh is increasing. The estimated number of death due to AIDS in Bangladesh is 68in 2001 which is gradually increasing and in 2015 it stands at 868 . The highest number of death due to AIDS is found in Pakistan and its trend is also increasing. The theoretical trend of HIV/AIDS prevalence in Bangladesh forecast that the prevalence rate will be $0.021 \%$ in 2020. The trend of HIV/AIDS awareness level in Bangladesh is found to be increasing over the year. The awareness level in Bangladesh is about $80 \%$ in 2014 among which male are $90 \%$ and female are $70 \%$. Finally, from the result of the present study it can be conclude that with the increase of the awareness level the number of new HIV infection in Bangladesh tends to decrease.
\end{abstract}

Keywords: HIV, AIDS, Prevalence, HIV Infection, Awareness

\section{Introduction}

The first case of HIV/AIDS epidemic recognized internationally in 1981[1], but in Bangladesh the first case was detected in 1989[2]. Prior to this first case, the government of Bangladesh (GoB) initiated early response to fight against this epidemic in 1985 [2, 3]. Since the spread of HIV/AIDS epidemic, Bangladesh has experienced a large number of HIV/AIDS infections, deaths and also gathering intervention strategies and implementing prevention program. In 2014, a total of 433 new cases of HIV infection, 251 new AIDS cases, and 91 deaths due to AIDS were reported (BDHS 2014) in Bangladesh [4]. The number of HIV-positive people in Bangladesh was 1,207 in 2007 [2], which increase to 3,674 in 2014 (BDHS 2014) [4]. The estimated number HIV/AIDS case remains at 8,900 in Bangladesh. Although, Bangladesh is still considered as a low-prevalence country for HIV/AIDS epidemic [5], it remains vulnerable to an HIV epidemic because of the high prevalence in the neighboring country. The awareness about
HIV/AIDS is very important to prevent the deadly consequence of the disease. Nowadays, the awareness in Bangladesh is rising $[6,7,8]$ and males are more aware than females $[9,10]$. To understand the level and trends towards the HIV/AIDS epidemic and awareness, this research tries to illustrate some graphical representation of the level and trends of the HIV/AIDS epidemic and it's awareness in Bangladesh. The trend of number of new HIV infection was rising until 2008 but with the increase of the awareness of HIV/AIDS the trend of number of new HIV infection is now decreasing in Bangladesh. The number of new HIV infection in Pakistan is high compared to other neighboring countries and its trend increasing over the years.

\section{Materials and Methods}

\subsection{Data Collection}

The data for this research have been extracted from Bangladesh Demographic and Health survey-2014(BDHS 2014) and UNAIDS. For the convenience of the research the 
country India is not included as India has too much high prevalence rate compared to other South Asian countries.

\subsection{Data Analysis}

A time series may have faster (or slower) increase at early stage and have a slower (or faster) increase at more recent time. In such a case better description of the time series is given by a non-linear cause rather than straight line. Here we used a parabolic trend by a second degree polynomial equation obtained by the method of least squares. We used descriptive statistics, graphs and time series and time series analysis for data analysis. To estimate the parameter and drawing the figures, the statistical package for social science (SPSS) version 20 and Microsoft Excel 07 is used.

\section{Results and Discussion}

The prevalence of HIV/AIDS in Bangladesh While most of the countries in the world experiencing a high prevalence rate in HIV/AIDS epidemic and its consequences, Bangladesh is still in the situation of low prevalence, which is a great success of the government of Bangladesh (GoB) and obviously its population. This is due to early response of the Gob against this epidemic. The current estimates suggest that the HIV prevalence rate is less than $1 \%$ among the groups of most-at-risk population in Bangladesh. The prevalence of HIV is now monitored annually among these groups at sentinel site across the country. In Bangladesh these most at risk groups are the representative of the HIV/AIDS epidemic related information, as the HIV risk in general people are very low in number. Where the prevalence rate in Bangladesh is $0.01 \%$, the prevalence rate in neighboring country India is $0.34 \%$ [11] and in Nepal this rate is $0.2 \%$ [12], which is relatively very high with respect to Bangladesh. The HIV/AIDS prevalence in Bangladesh is listed and shown in the figure below.

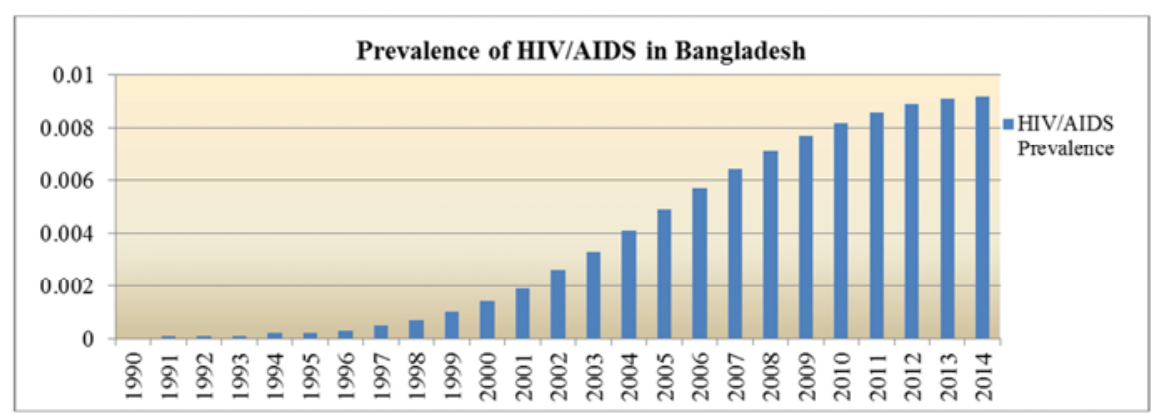

Figure 1. Trend of HIV/AIDS Prevalence in Bangladesh (\%).

From the above figure it is observed that the prevalence of HIV/AIDS is increasing over the years. In early 1991 the prevalence was only $0.0001 \%[12,13]$ which is very potty but with time the HIV/AIDS prevalence is increasing gradually. At the end of 2014 it stands at $0.0092 \%$ which is near to $0.01 \%$ [14]. Hence from the above figure we can conclude that the HIV/AIDS prevalence in Bangladesh has an increasing trend. As a comparative study we have listed the HIV/AIDS prevalence rate in different neighboring countries and shown in the figure below.

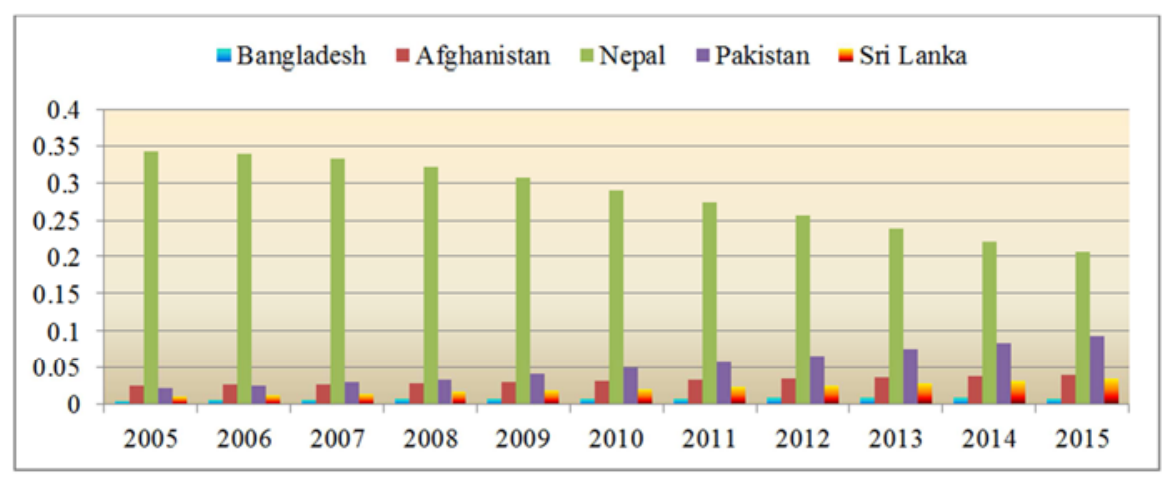

Figure 2. HIV/AIDS Prevalence in Different Countries of South Asia.

From the above figure see that the highest prevalence rate was in Nepal $(0.3416 \%)$ in 2005 which is decreasing over the years and the increasing trend is found in Pakistan where other countries have stable trend. The prevalence rate of HIV/AIDS in Bangladesh is 0.0085\% (in 2015) and if we see the prevalence rate in other neighboring countries the rate in Nepal is $0.206 \%, 0.0395 \%$ in Afghanistan, 0.0928\% in Pakistan and $0.0347 \%$ in Sri Lanka. Figure 2 shows that compared to other South Asian countries Bangladesh has very low HIV/AIDS prevalence rate.

According to UNAIDS report, the estimated number of AIDS related death in Bangladesh in 2001 is 68 which is gradually increasing and in 2015 it stands at 868 [5]. A table of estimated number of death due to AIDS in Bangladesh is given below 
Table 1. Death Due to AIDS (in number) in Bangladesh according to UNAIDS report.

\begin{tabular}{llllll}
\hline Year & Death & Year & Death & Year & Death \\
\hline 2002 & 98 & 2007 & 413 & 2012 & 762 \\
2003 & 139 & 2008 & 496 & 2013 & 806 \\
2004 & 194 & 2009 & 541 & 2014 & 834 \\
2005 & 262 & 2010 & 621 & 2015 & 868 \\
\hline
\end{tabular}

From table 1 we see that in 2001 the number of death due to AIDS was 68 but in 2015 it increases to 868 in Bangladesh. A graphical representation of HIV/AIDS related data provided by UNAIDS is given in the diagram below

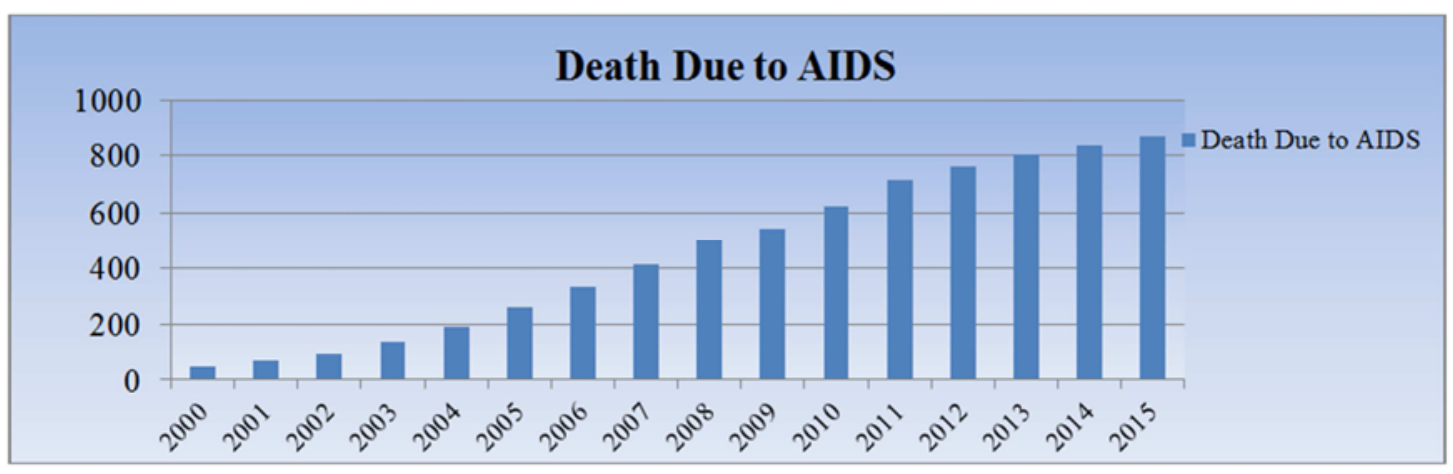

Figure 3. Death due to AIDS (in number) in Bangladesh according to UNAIDS report.

From Figure 3 observe that the number of death due to AIDS in Bangladesh follows an increasing trend.

The data of death due to AIDS in different South Asian countries have been extracted from the UNAIDS spectrum estimate. A graphical representation of the death due to AIDS in different South Asian countries is given below:

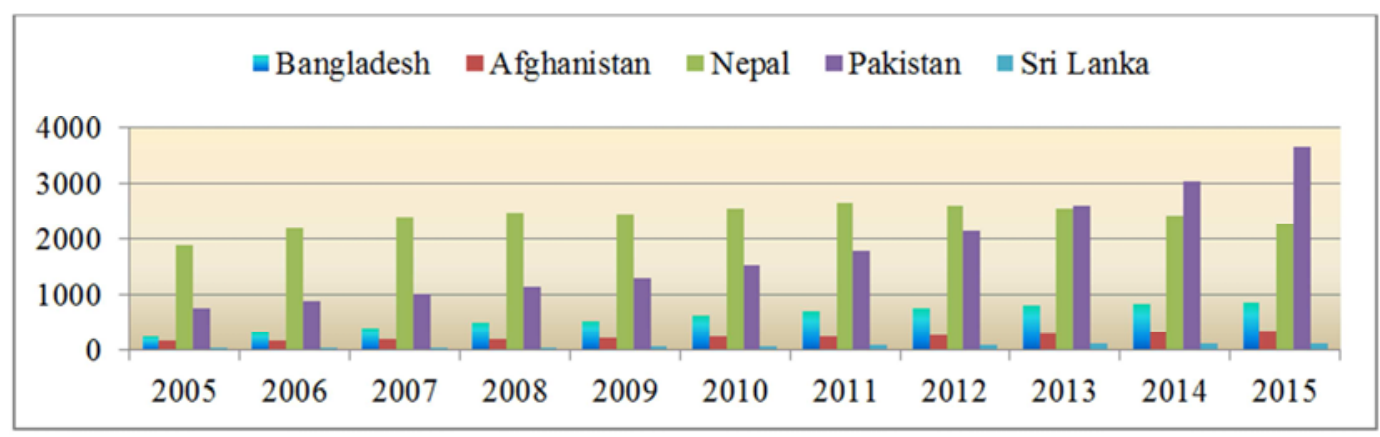

Figure 4. Deaths Due to AIDS in Different South Asian Countries.

When compare the number of death due AIDS in Bangladesh with other neighboring counties, it seems that Bangladesh is steel in good position but not out of danger [11]. From the Figure 4 see that, in Nepal the number of death due to AIDS increased in a slide amount but it started to decrease from 2011 to yet. In Pakistan the number of HIV/AIDS related death is increasing vulnerably. The number was 762 in 2005 but at the end of 2015 it increases to 3,642 . In Bangladesh the number of death in 2000 was 262 but the number is increasing with a steady manner and now it is 868 . The minimum number of death due to AIDS is found in Sri Lanka. The number of people living with HIV in
Bangladesh is increasing day by day. Although, the Government of Bangladesh provides the support and service to the most at risk groups, the dickens of this deadly epidemic does not leave its malefactor impact. Here in Bangladesh, the general population has a different view to the people who have HIV positive status, and are thrown away from the society [11], as there are some misconceptions among the people in Bangladesh and also lack of knowledge about HIV/AIDS [15]. The general misconceptions among the people that it is risky to walk, sharing food, use bathroom together and hugging with HIV infected person. A short list of number of people living with HIV is given below.

Table 2. People Living with HIV in Bangladesh during 1991-2014 by number and sex.

\begin{tabular}{llllllll}
\hline Year & Female & Male & All sex & Year & Female & Male \\
\hline 2003 & 546 & 2036 & 2582 & 2009 & 1922 & 4839 \\
2004 & 730 & 2546 & 3276 & 2010 & 2178 & 5184 \\
2005 & 941 & 3076 & 4016 & 2011 & 2399 & 7362 \\
2006 & 1168 & 3551 & 4720 & 2012 & 2589 & 7837 \\
2007 & 1411 & 4010 & 5421 & 2013 & 2745 & 5614 \\
2008 & 1659 & 4453 & 6112 & 2014 & 2877 & 5695 & 5748 \\
\hline
\end{tabular}




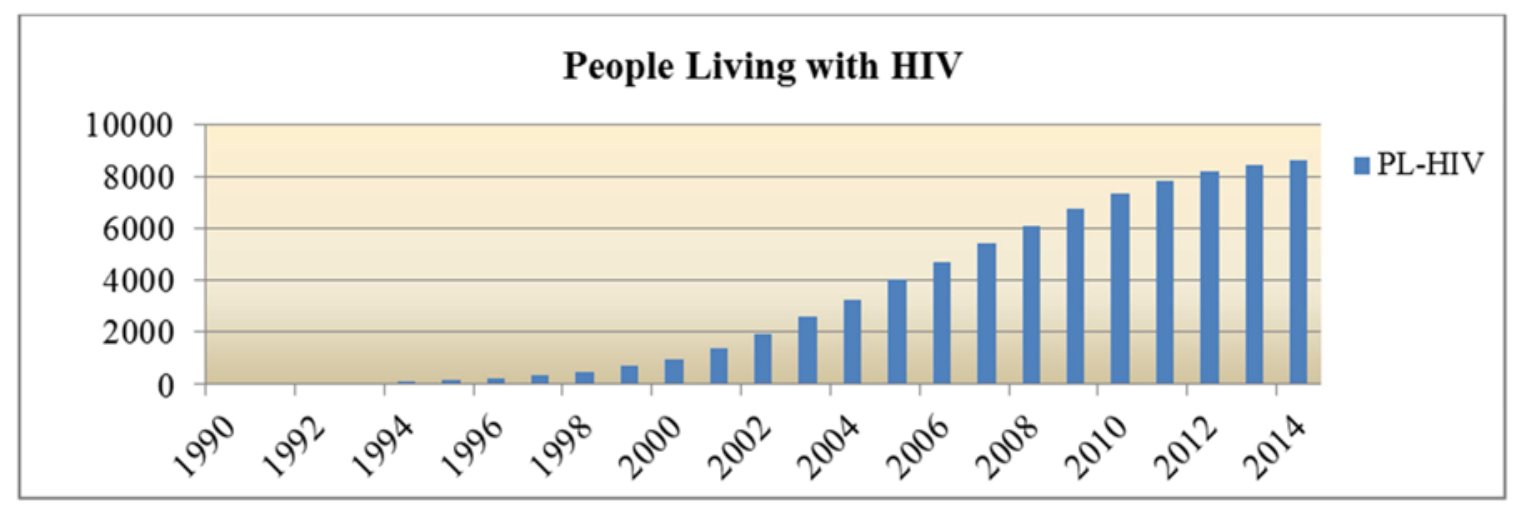

Figure 5. People Living with HIV in Bangladesh by number.

Table 2 and figure 5 illustrate that, In Bangladesh the estimated number of people living with HIV is 8,900 , among which women age 15 and up living with HIV is 2,900 and children are estimated is $<500$. If we compare with neighboring country India, the estimated number of people living with HIV is 33.4 million [5]. If we see the epidemic in Nepal, the number of people living with HIV is 39,000 and women aged 15 and up is estimated 13,000 and the children estimated as 2,000 .

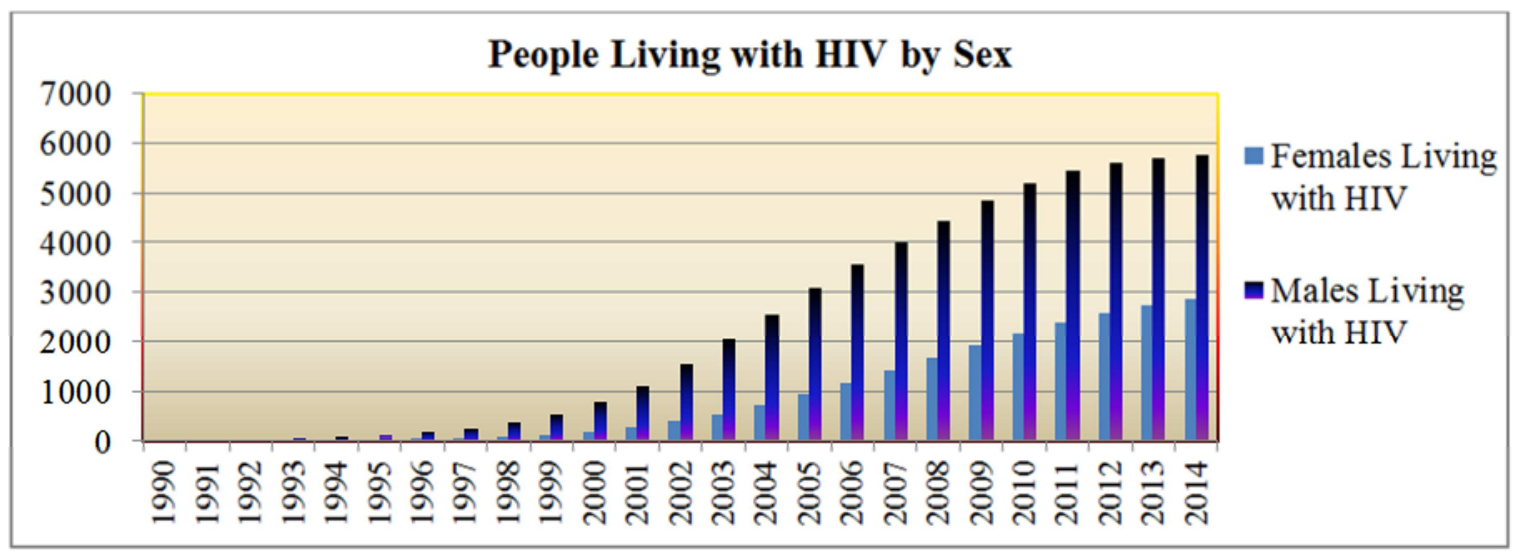

Figure 6. A People Living with HIV in Bangladesh by sex (in number).

If compare the people living with HIV/AIDS by sex, we observe from figure 6 that males are more infected than females [8]. Although, awareness in males are high [16] but the prevalence among them is high compared to females. This may be by the cause that males are three times more vulnerable to transmission of this epidemic than females [17]. Among the males who sex with males and also exposed to anal sex are more vulnerable to spread of this pandemic, which facilitate the spread of HIV virus in very easy way [18, 19, 20]. In 2010 the estimated number of females living with HIV was 2,178 and the number of males was 5,184 but at the end of the year 2014 it rises to 2,877 and 5,748 for females and males respectively.

The number of new HIV infection

From the figure 7 the number of new HIV infection is seems to be a good shaped that the number becoming slower over the time moving. In the mid age of the epidemic in Bangladesh the number of new infection was growing with a steady line, but with the enhancement of the awareness about HIV/AIDS the number of new infection is in the way of abridgements.

Table 3. The number of new HIV infection (in number) in Bangladesh during 1992-2014.

\begin{tabular}{lllll}
\hline Year & No. & Year & No. & Year \\
\hline 1992 & 20 & 2000 & 355 & 2008 \\
1993 & 27 & 2001 & 491 & 2009 \\
1994 & 42 & 2002 & 669 & 2010 \\
1995 & 58 & 2003 & 802 & 2011 \\
1996 & 82 & 2004 & 923 & 2012 \\
1997 & 122 & 2005 & 1047 & 2013 \\
1998 & 172 & 2006 & 1090 & 1225 \\
1999 & 249 & 2007 & 1171 & 1154 \\
\hline
\end{tabular}

The table 3 represents the number of new HIV infection in Bangladesh during the year 1992 to 2014. 
A graphical representation of the number of new HIV infection in Bangladesh during 1990-2014 is given below

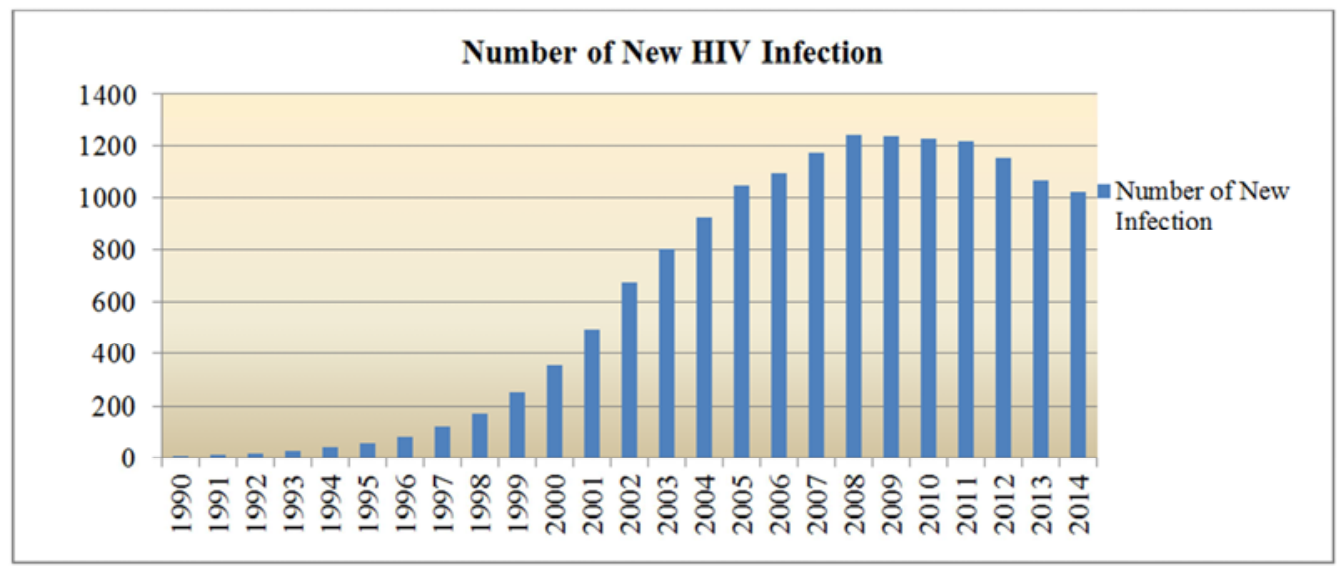

Figure 7. Number of New HIV Infections in Bangladesh (in number).

In Bangladesh the number of new infection was high in 2008 and the amount was 1,242, which was the peak of the raising portion of the figure. Until this it was an alarming sign for Bangladesh and obviously fearful for the GoB and its people but in 2014 the estimated number of new HIV infection in Bangladesh is 1,021 i.e. a decreasing trend is observed after the year 2008. While in neighboring country in India the estimated number of new infection of HIV is
130,000. In 2003 the estimated number of new infection was 81 per 100,000 people in Nepal. As of December, 2014, 16,983 cases of new infection were officially reported in Pakistan. Compared to both of these neighboring country Bangladesh is still a low prevalence country, but the risk of spreading this epidemic is still high as the our neighboring country India is world $3^{\text {rd }}$ largest HIV/AIDS prevalence country.

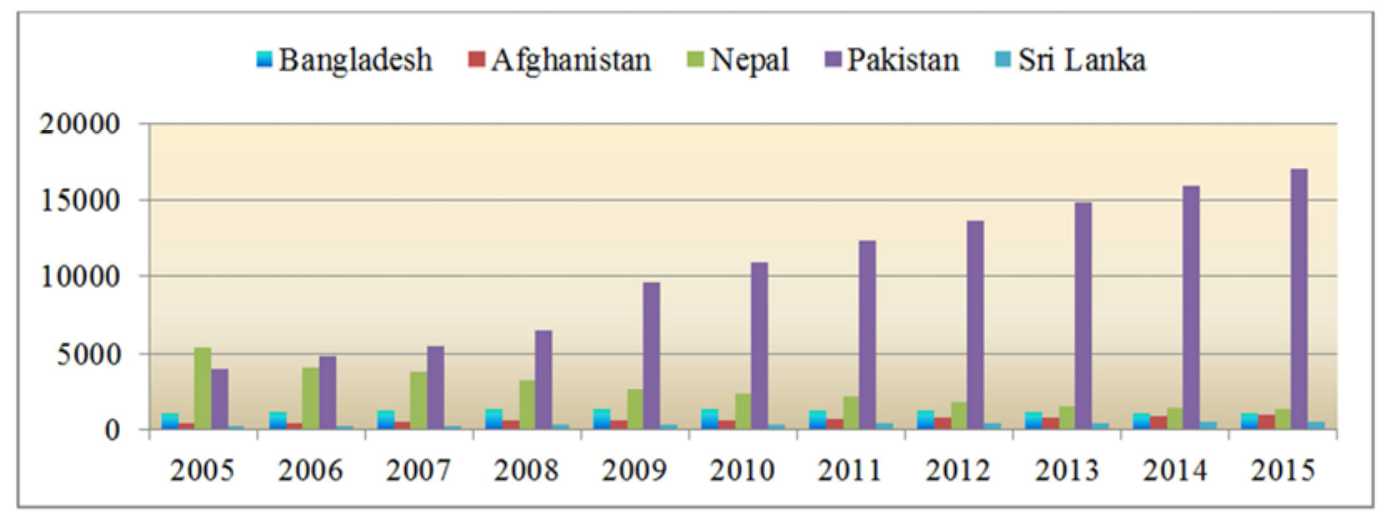

Figure 8. Number of new HIV infection in different South Asian counties.

It is quite good for the Bangladesh that the number of new infection of HIV/AIDS is decreasing. If compare with different neighboring countries and figure 8 shows that it is seems that, the number of new infection is high in Pakistan and the low new infectious country is Sri-Lanka but a significant decrement is found in Nepal, it start with 5,445 in 2005 but at the end of 2015 it decreases to 1,331. In this context Bangladesh has gained also a significant improvement that, in 2005 the number of new infection was 1,128 which decreases to a little amount to 1,070 in 2015 . The number of new HIV infection decreased is little but is great news for Bangladesh. Hence, can say that with compared to other country Bangladesh is still in a good position. The Government of Bangladesh as well as its people needs to be careful about this pandemic to reduce the number of new infection as well as to get rid of this dangerous disease.
Theoretical trends of HIV/AIDS epidemic in Bangladesh $\mathrm{HIV}$ in Bangladesh has continued to remain at relatively low levels in the most at risk population groups [21]. The early and sustained HIV prevention programs targeting high risk groups backed by a state-of-the-art surveillance system is found to be the main reason for the low prevalence in Bangladesh [22]. The trend line show in Figure 9 is a quadratic trend representing the current and future trends towards the HIV prevalence in Bangladesh. Since the levels of HIV/AIDS by yearsis highly skewed, $2^{\text {nd }}$ degree polynomial curve has been displayed instead of linear curve. The equation used here is a quadratic equation andit is

$$
Y_{i}=0.003+0.001 * t+8.593 * 10^{-6} * t^{2}
$$

and the value obtained by this equation is given in the table below 


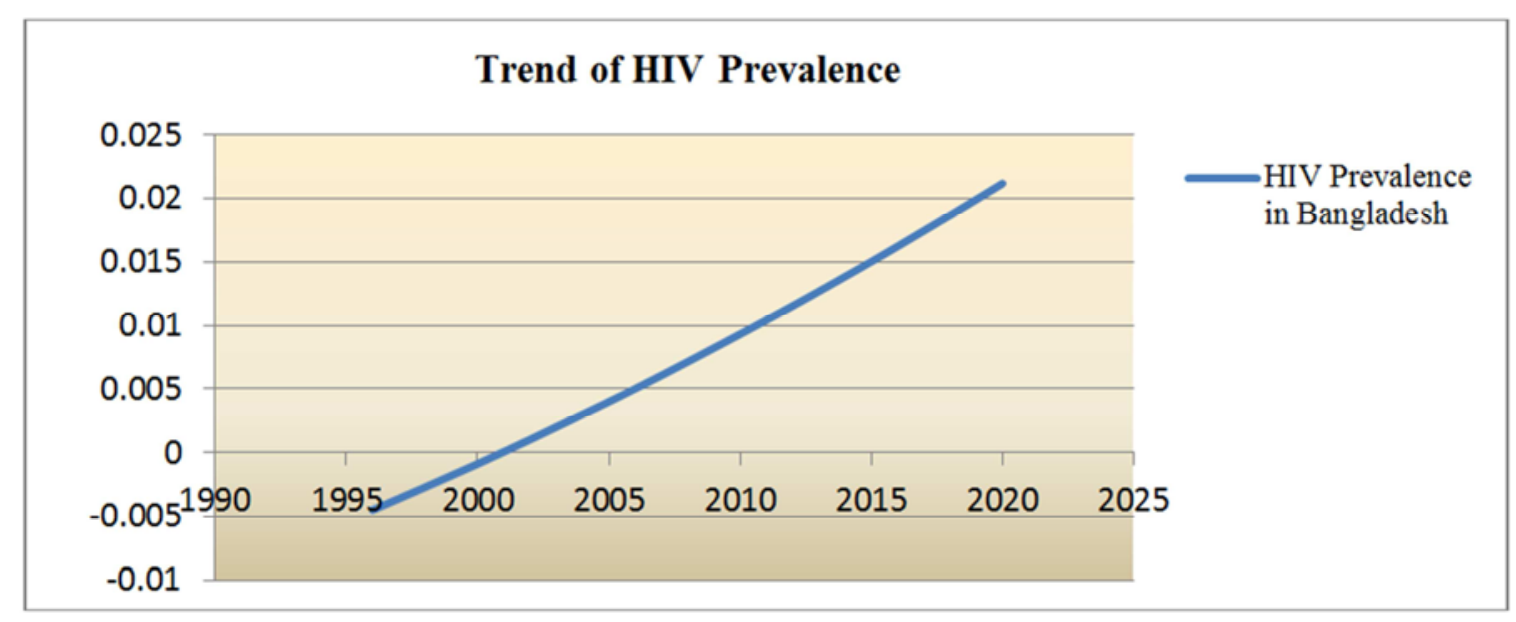

Figure 9. Trend of HIV Prevalence in Bangladesh (\%).

The Figure 9 shows that the current prevalence rate of HIV/AIDS epidemic is less than $0.013 \%$ but in 2020 it may rise up to $0.021 \%$, which is not a good sign for Bangladesh. So the GoB should need to take further action to avert such type of pandemic. Since the level of the number of the people living with HIV/AIDS is highly skewed, a second degree polynomial is fitted to obtain the expected number of people living with HIV in Bangladesh; the equation used here is as follows

$$
Y_{i}=2691.61+470.09 * t+13.797 * t^{2}
$$

The solution of the above equation is given below

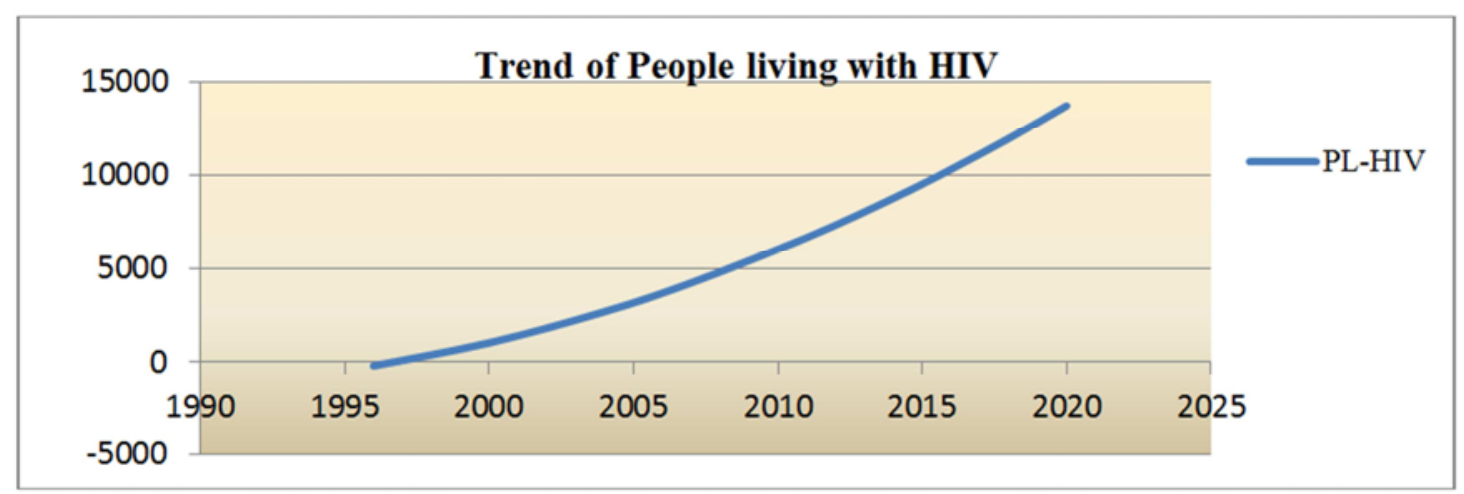

Figure 10. Trend of People Living with HIV in Bangladesh (in number).

Globally, the HIV/AIDS epidemic claimed more than three million lives in 2001, and an estimated five million newly acquired HIV [23]. There are now 42 million people living with the virus [5]. South Asia accounts for 10 percent of these numbers [24]. In Bangladesh, the trend line in figure 10 shows that in 2014 the number of people living with HIV is 8772 , in current i.e. in 2016 the number of living people is 10,319 and in 2020 it will arrive at 13,745.

All over the world the number of new HIV infections is increasing day by day.

In Bangladesh, the trend of new HIV Infection mentioned in figure 11 shows that the number of new infection was raising steadily up to 2014 which amount 1178 , but after this period the trend line changes its direction and going downwards. Since the level of HIV new infection is highly skewed by years, a second degree polynomial is considered to make a possible trend line. The equation considered here is

$$
\mathrm{Y}_{\mathrm{i}}=773.73+76.563 * \mathrm{t}-3.615 * \mathrm{t}^{2}
$$

And the solution for different year is given below

Table 4. Trend of HIV New infection in Bangladesh.

\begin{tabular}{ll}
\hline Year & HIV New Infection \\
\hline 1996 & \\
2000 & 409 \\
2004 & 773 \\
2007 & 970 \\
2011 & 1132 \\
2014 & 1177 \\
2016 & 1171 \\
$2018^{*}$ & 1137 \\
$2020^{*}$ & 1073 \\
\hline
\end{tabular}

*Forecast

The table 4 contains the information regarding the theoretical trend of HIV new infection in Bangladesh

The graphical representation of the trend of HIV new infection is shown below 


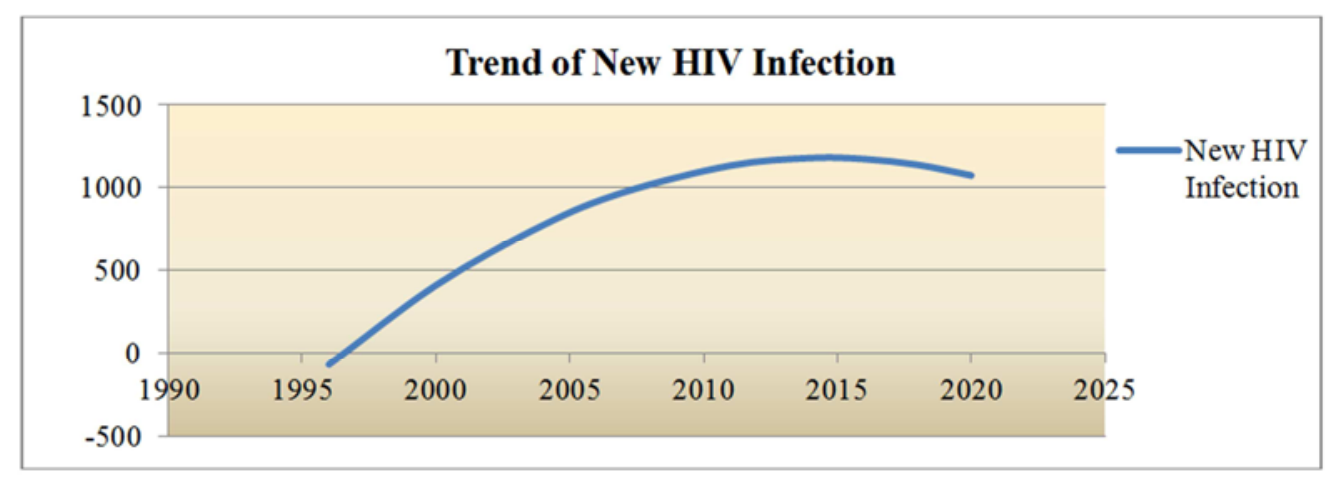

Figure 11. Trend of HIV New Infections in Bangladesh (in number).

The amount showed by trend line is approximately nearly to the amount estimate by the UNAIDS spectrum estimates. From the trend line it can be said that in 2016 and 2018 the number of new infection will be 1172 and 1137 respectively. And finally it can be said from the aforesaid figure that in 2020 the number of new HIV infected people will be 1073 , which is a good indication that the trend of number of new HIV infected people is decreasing and hope, will diminish completely from Bangladesh.

Trends of HIV/AIDS awareness in Bangladesh

Since 1987, when there is no identified case in Bangladesh $[25,26,27]$, the Government of Bangladesh (GoB) has been implementing HIV prevention program through awarenessraising activities. Over the year, the HIV program has grown in size and quality has involved a wider network of stakeholders. The program has increased its coverage of most-at-risk populations, which now include young people. There have been various efforts to prevent HIV transmission, such as public health education through the media and program activities by both government and NGOs, particularly with groups considered to be at high risk for transmission of HIV/AIDS. To understand the patterns of awareness of HIV/AIDS straightforwardly, the levels over different time points are displayed in the figure 12 .

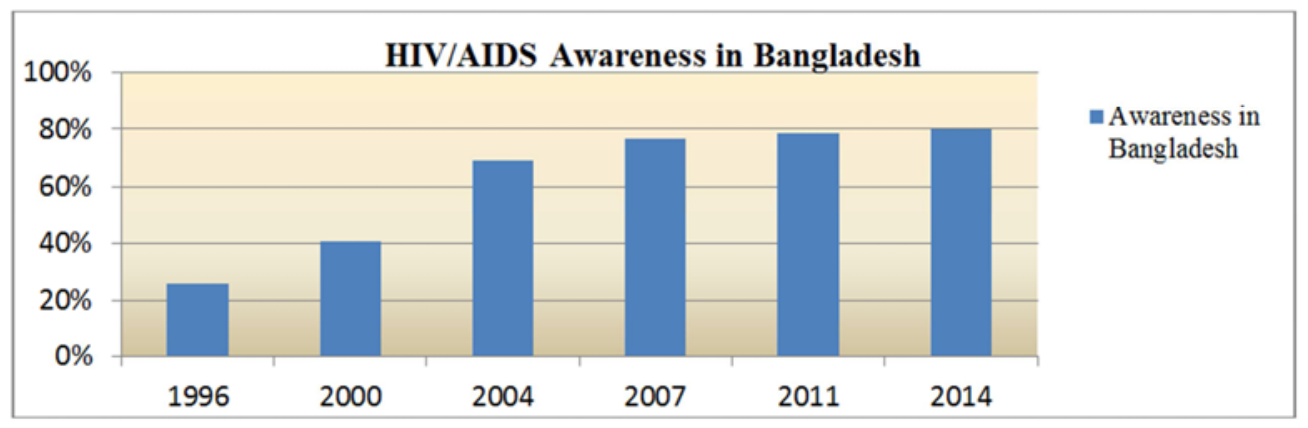

Figure 12. Awareness of HIV/AIDS in Bangladesh.

From the figure 12 see that in early 1996 the awareness level in Bangladesh was very low, as the HIV pandemic was not posing threat in the country as well as over the world. But with the increase of the consequences of this epidemic, the administration and county policymakers enhance their strategies to raise the awareness among the most-at-risk population and general people specially the youth. As this response, the feedback was obtained a good result, and is still continuing with increasing awareness.

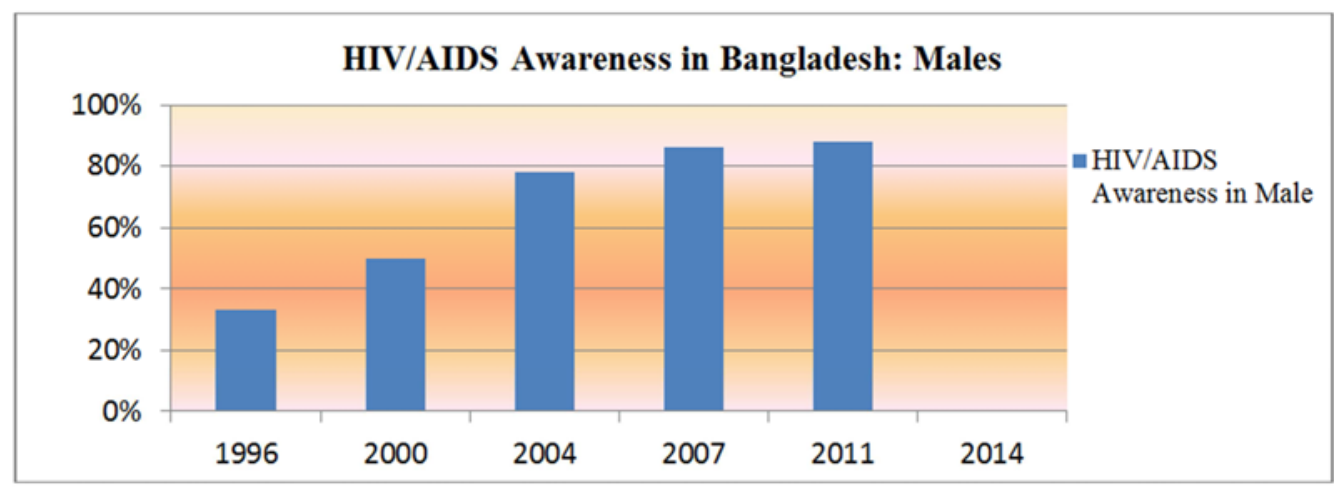

Figure 13. HIV/AIDS Awareness among Males Aged 15-49 in Bangladesh. 
From figure 13 we observe that, in Bangladesh the males are more susceptible to know about the knowledge about HIV/AIDS than females.

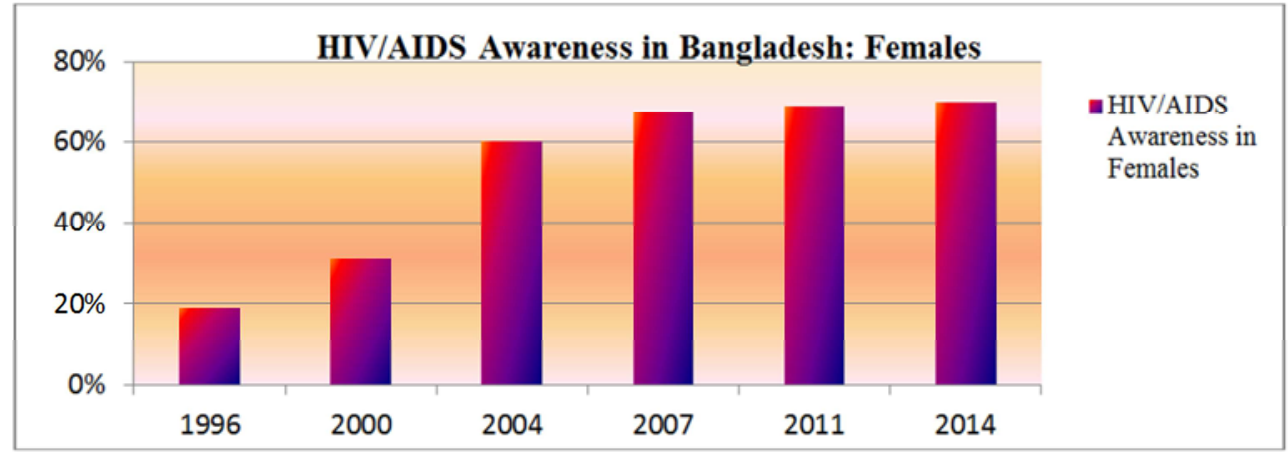

Figure 14. HIV/AIDS Awareness among Ever Married Women aged 15-49 in BD.

At the end of the year 2014 the HIV/AIDS awareness level in Bangladesh is about $80 \%$, in which males are $90 \%$ and $70 \%$ of the females respondents are aware about HIV/AIDS epidemic. A probable trend line on the basis of the of the previous awareness level have been drawn below. Since the level of awareness is skewed a second degree polynomial is fitted to find the probable trend. The equation of the trends line is

$$
Y_{i}=65.4+3.59 * t-0.21 * t^{2}
$$

The value of $Y_{i}$ for different value of $t$ is shown below

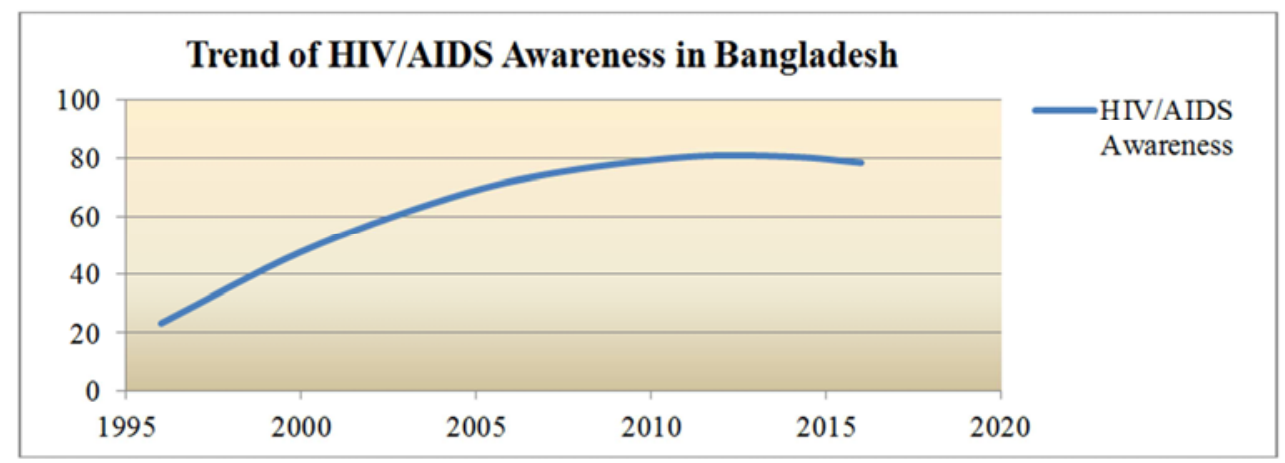

Figure 15. Trend of HIV/AIDS awareness (\%) in Bangladesh.

The above figure 15 reveals that the from the initial stage, the trend of awareness is raising upward and it looks that awareness trends reach over the $80 \%$, but in the tail of the trend line it seems to slight fall, which is not as expected.

Now illustrate a comparative study based on the awareness and its effect on the HIV/AIDS epidemic. As the awareness level is at percentage unit and the number of new infection is at thousands unit, convert both of them in a similar standard unit for best comparison and can easily draw out diagram. It facilitates to show the level in same standard form. To best understand the actual effect of HIV/AIDS awareness on HIV/AIDS epidemic draw a diagram based on the level of the awareness and new infection of HIV/AIDS.

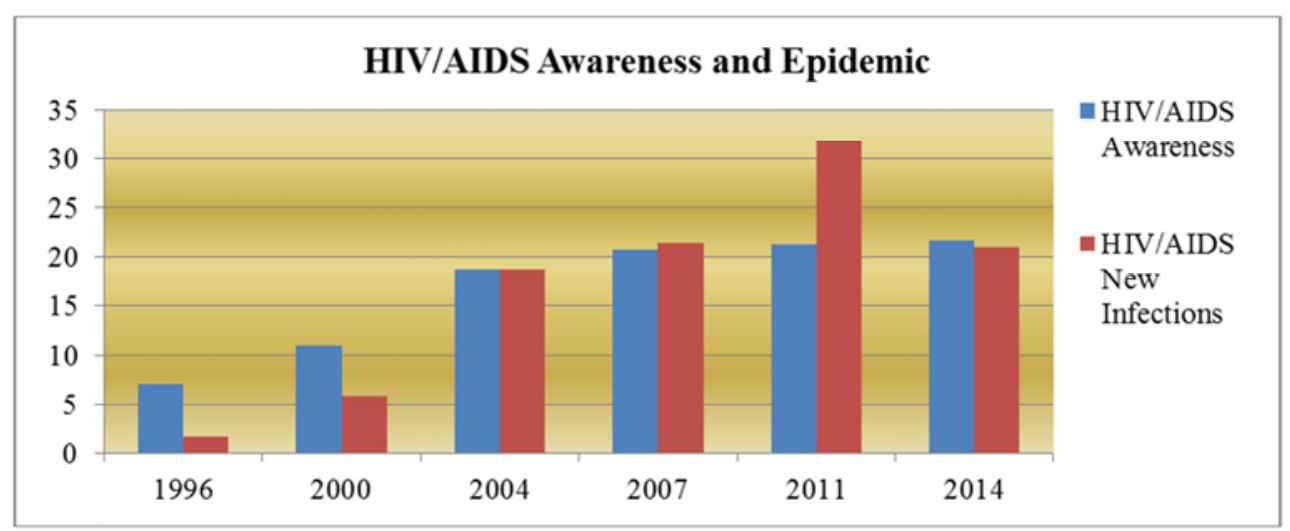

Figure 16. The Presentation of Relativity of HIV/AIDS Awareness and Epidemic in Bangladesh based on Actual Trends. 
From the Figure 16 see that the level of awareness is rising steadily but the level of number of new infection fluctuates over the periods. In the period 2007-2011 it seems that the number of new infections was high but the awareness level is as usual position, this may be cause due to the world wide spread of HIV/AIDS epidemic in this decade. This obviously makes impact almost every country over the world. But in the last period, the level of the number of new infections is less than the level of awareness, which indicate that the number of new infections getting lower with the increase of the awareness. Finally, it can be conclude that awareness is most important for minimizing the impact of HIV/AIDS epidemic and its consequences. Hence the Government should need to increase awareness raising program and improve intervention strategies against this deadly epidemic.

\section{Conclusion}

This study examined the extent and determinants of HIV knowledge and awareness level of Bangladesh. This finding indicate that HIV prevention programs have a lot to improve in creating general awareness and clarifyingmisconception regarding mode of transmission of the disease. The HIV/AIDS prevalence rate in Bangladesh is $0.01 \%$, which is very low compared to other countries in the world but it has an increasing trend. The trend of number of new HIV infection in Bangladesh has been decreasing since 2008 but prior to 2008 it had an upward trend. In 2008, the number of new HIV infection was 1,242 but in 2014 it reduces to 1,021 . The overall awareness level in Bangladesh is $80 \%$ of which females are $70 \%$ and males are $90 \%$. With the increase of the awareness level the number of new infection is seems to be decreasing. The theoretical trend also forecast that the number of people living with HIV and the number of new HIV infection in Bangladesh will be 13,745 and 1,073 respectively in 2020. The trend of HIV/AIDS awareness level in Bangladesh is found to be increasing over the year.

\section{References}

[1] Centers for Disease Control (CDC). (June 1981). "Pneumocystis pneumonia -Los Angeles". MMWR Morb. Mortal. Wkly. Rep. 30(21): 250-2. PMID 6265753.

[2] Bangladesh Mitra and Associate, National institute of Population Research and Training, and Macro International inc., Bangladesh Demographic and Health Survey, 2007.

[3] Bangladesh Mitra and Associate, National institute of Population Research and Training, and Macro International inc., Bangladesh Demographic and Health Survey, 2011.

[4] [Bangladesh Mitra and Associate, National institute of Population Research and Training, and Macro International inc., Bangladesh Demographic and Health Survey, 2014.

[5] UNAIDS, "UNAIDS spectrum estimates 2014," UNAIDS, 2014.
[6] Tasnim A, Sharful I k, Fariha H, Nafisa L H, Lars H, M Mushtaq $P$, Mahbub E $H$, Isabella S. HIV/AIDS in Bangladesh., ICDDR, B, Mohakhali, Dhaka 1212, Bangladesh. Journal of Health, Population and Nutrition, Vol. 26, No. 3, (Sep. 2008), pp. 311-324.

[7] Sabrina Z M, Faiz A B, Sheikh M S I. Knowledge and perceptions of sexually transmitted diseases, HIV/AIDS, and reproductive health among female students in Dhaka, Bangladesh. 2015.

[8] Khan M A, Rahman M, Khanam P A, Barkat-e-Khuda, Kane T T, Ashraf A. Awareness of sexually transmitted disease among women and service providers in rural Bangladesh. Int J STD AIDS 1997; 8:688-96.

[9] Hossain M, Mani KK, Sidik SM, Shahar HK, Islam R. Knowledge and awareness about STDs among women in Bangladesh. BMC Public Health 2014;14:775.

[10] Sarafian I. Process assessment of a peer education program for HIV prevention among sex workers in Dhaka, Bangladesh: A social support framework. Soc Sci Med 2012;75:668-75.

[11] AVERT, "HIV and AIDS in Asia \& the pacific regional overview", AVERT, 2016.[12] UNAIDS,"Fact sheet November 2016," UNAIDS, 2016.

[12] National AIDS/STD Programme (NASP). (2010)Government of the People's Republic of Bangladesh, editor. 3rd National Strategic Plan for HIV and AIDS Response, 2011-2015. Dhaka: National AIDS/STD Programme (NASP);

[13] UNAIDS,“UNAIDS prevention gap report 2016,” UNAIDS, 2016.

[14] Mondal N, Rahman N, Rahman O, AkterH. The level of awareness about HIV/AIDS among ever-married women in Bangladesh. Food Pub Health 2(3)73-78.

[15] Sarafian I. Process assessment of a peer education program for HIV prevention among sex workers in Dhaka, Bangladesh: A social support framework. Soc Sci Med 2012;75:668-75.

[16] Estebanez P, Russell N K, Aguilar M D, CifuentesI, Zunzunegui $\mathrm{M}-\mathrm{V}$, \& McPherson K. Determinants of HIV prevalence amongst female IDU in Madrid. European Journal of Epidemiology, Vol. 17, No. 6(2001), pp.573-580.

[17] Chan PA, Khan OA. Risk factors for HIV infection in males who have sex with males (MSM) in Bangladesh. BMC Public Health $2007 ; 7: 153$

[18] G/Moges, Mariam. Sexual Orientation, Practices and HIV Risk Behavior of Young People in Addis Ababa High Schools. School of Graduate Studies, Addis Ababa University, Addis Ababa, July 2007.

[19] P. Estebanez, N. K Russell, M. D. Aguilar, I. Cifuentes, M. V. Zunzunegui and K. McPherson.

[20] Determinants of HIV prevalence amongst Female IDU in Madrid. 2001.

[21] M. Asaduzzaman Khan. Knowledge on AIDS among Female Adolescents in Bangladesh: Evidence from the Bangladesh Demographic and Health Survey. Icddr'b, Journal of Health, Population and Nutrition, Vol.20, No. 2 (June 2002), pp. 130-137.

[22] Shariful Islam S M, Biswas T, Bhuiyan F A, Islam M S, Rahman M M, Nessa H. Injecting drug users and their health seeking behavior: A cross-sectional study in Dhaka, Bangladesh. J Addict;2015:756579. 
[23] UNICEF, Girls, HIV/AIDS and education. New York: UNICEF. World Food Programme (2013).

[24] South Asia High-Level Conference: Katmandu, Nepal, Acceleration the Momentum in the Fight Against HIV/AIDS,2003.

[25] National Institute of Population Research and Training, Dhaka, Bangladesh. Bangladesh Demographic and Health
Survey 2014. Dhaka: National Institute of Population Research and Training; 2013.

[26] World bank. HIV/AIDS in Bangladesh, Jul-2012.

[27] UNICEF. HIV and AIDS in Bangladesh. March, 2009. 